\title{
Towards an Understanding, Through Action Research, of the Socio-Organizational Issues Impacting on Mobile Technology Adoption and Diffusion Within a Small-to- Medium South African Construction Company
}

\author{
Jacques Abrahamse • Hugo Lotriet
}

Published online: 10 August 2011

(C) Springer Science+Business Media, LLC 2011

\begin{abstract}
We investigated, through an action research approach, social issues that impact on mobile technology adoption and diffusion in a professional construction management team of a small-to-medium sized South African construction company. The outcome of the study resulted in a framework of thinking that integrates social factors at individual and organisational levels that impacted on the adoption of mobile technologies in the organisation. At the methodological level the study is part of a limited collection of papers that used AR in the study of technology adoption and diffusion and it presents an example of the capability of AR as a method to allow for the integration of the social contexts of users into adoption frameworks.
\end{abstract}

Keywords Socio-organisational issues - Mobile technology · Adoption - South Africa · Construction · Action research

\section{Introduction}

The construction sector presents organisations with fairly unique challenges in terms of Information and Communication Technology (ICT) adoption and use. These include the temporally and spatially fragmented nature of projects and collaboration on projects as well as the multi-disciplinary nature of collaboration on projects (Rezgui 2007a, p. 97).

The discourse on ICT adoption and use has been dominated by the use of the technology adoption model (TAM) and associated approaches (Venkatesh et al. 2007, p. 267). These approaches nevertheless present persistent challenges, especially in understanding the significant impact of user context on IT adoption and use and the integration of such understanding into frameworks of IT adoption and use (Eckhard et al. 2009, p. 11). In the context of the construction industry, this constraint becomes significant. In order therefore

\footnotetext{
J. Abrahamse

Department of Informatics, University of Pretoria, Pretoria, South Africa
}

H. Lotriet $(\bowtie)$

School of Computing, University of South Africa, P.O. Box 392, UNISA, Pretoria 0003, South Africa e-mail: lotrihh@unisa.ac.za 
to overcome this constraint, we have, for the project described in this paper, taken a sociotechnical point of departure for the technology adoption process. Viewing the ICT adoption process as a complex socio-technical phenomenon (combined with the requirement for the lead researcher to produce tangible results in the organisation where the study was undertaken) indicated the appropriateness of an action research (AR) approach.

The study was located in South Africa. Because of the nature of technology challenges facing the construction industry (described in more detail in section "Context for the research") and the associated outcomes that had to be achieved in practice the research scope was limited to mobile technologies.

The contribution of this paper is a thinking framework that represents a substantive theory of mobile technology adoption for the South African company where the study was undertaken. At a more general level the study argues that integration of contexts at both individual and organisational level is essential in order to understand technology adoption in construction companies. This makes the construction industry an interesting area for doing ICT adoption studies using non-mainstream (and particularly socio-technical) approaches. Furthermore the study is an example of the appropriateness of AR as a method to do this.

The paper is structured as follows: Firstly the context for the research is described, with specific reference to ICT adoption and diffusion processes in the construction industry and the need for a socio-technical understanding of these processes. Secondly some background is provided on the South African organisation where the research was undertaken and an initial thinking framework for mobile technology adoption in the organisation is presented. Thirdly AR as method is motivated and the research design for this particular project is presented. Fourthly details of the various AR cycles are reported. Finally a summary and conclusions are presented.

\section{Context for the Research}

\section{ICT Adoption and Diffusion in the Construction Industry}

It has been argued that achievement of strategic objectives (e.g. profitability) for companies within the construction industry (in South Africa) is not achievable without the proper adoption of innovative technological solutions (Yetton et al. 1994, p. 57). Nevertheless the construction industry is considered to be lagging behind other sectors in the use of information technology (Nova Scotia Construction Sector Council 2010, p. 13, Rowlinson and Croker 2006, p. 154), and a significant persistent issue considered to be the reason for this is related to adoption and implementation of ICT (Nova Scotia Construction Sector Council 2010, p. 13).

The construction sector has various unique characteristics that influence and are influenced by the adoption and use of ICT. One of the main factors contributing to the uniqueness of the construction sector relate to the specific structuring of construction projects, with the separation of design and construction phases of projects resulting in specific challenges relating to the 'technical interdependence' versus 'organisational independence' and the intricacies these relationships impose on stakeholder communication and the technologies used to implement communication (Rowlinson and Croker 2006, p. 155). In this regard it has been argued that a significant distinction should be made between the use of ICT in 'permanent line organisations' and its use in 'temporary' organisations that constitute the various individual construction projects-a distinction which is not often made in literature on ICT use (Jacobsson and Linderoth 2010, p. 13). 
In addition, the localized nature of construction projects mean that often small local operations can compete successfully with larger organizations, thus reducing the pressure on the industry sector to adopt ICT for the sake of better overall efficiency and competitiveness (Jacobsson and Linderoth 2010, p. 17). The unique nature of these 'localized' and fairly autonomous projects result in challenges to standardize any information-related processes thus reducing the incentive to employ ICT extensively (Jacobsson and Linderoth, op. cit.). High maturity levels of role players are therefore required for users to successfully adopt and use technology in this context (Rowlinson and Croker 2006, p. 155). Specifically it has been found that staff members on construction sites are lagging in the use of, and satisfaction with ICT as strategic tool (Jacobsson and Linderoth 2010, p. 13; Rowlinson and Croker 2006, p. 167).

Some of the more practical (but nevertheless persistent) challenges faced by the construction industry are firstly that information technologies are easier to implement in a clean and stable environment and secondly that workers and technology are exposed to various extreme conditions like natural elements, crime and unacceptable mobile service provider network infrastructure (Bowden et al. 2006, p. 664). These translate into issues of portability, 'ruggedness' of solutions and the usability of interfaces for information exchanges (Nova Scotia Construction Sector Council 2010, p. 12).

The Need for a Socio-technical Perspective on ICT Adoption in the Construction Sector

The main attributer to ICT adoption and use in construction has been argued to be largely socio-organizational and cultural, rather than technical (Rezgui 2007a, p. 110; Songer et al. 2001, p. 9). Context is considered specifically relevant to mobile adoption at construction site level (Nova Scotia Construction Sector Council 2010, p. 18). Seen from this perspective, the ICT adoption process in construction companies becomes a complex change process affected by various contextual factors including economic conditions, organisational politics, cultural history, role players' 'frames of reference' and others in interaction with the technology being adopted (Jacobsson and Linderoth 2010, p. 14). Love et al. (2001, p. 34) list these socio-organizational issues as (1) "resistance from management" (especially middle management); "lack of investment in an IT infrastructure"; "lack of IT awareness"; "lack of employee education and training"; "degree of organizational change required"; "a belief that the industry is doing well without IT", with two main barriers being (2001, p. 36) "lack of employee knowledge" and "a reluctance to form collaborative partnerships" (2001, p. 36). The findings of Peansupap and Walker (2006, p. 370) support the notion of inadequate employee knowledge and in addition indicate that that senior business managers' lack of experience in ICT may ultimately lead to user resistance and lack of confidence in ICT implementation strategies.

The importance of training is highlighted by various authors (Peansupap and Walker 2006, p. 371; Love et al. 2001, p. 34). Aspects such as content, delivery method and quality of training all have an impact on adoption and diffusion of ICT. In addition it has been argued that training should not only focus on technical knowledge, but specifically on the application of the ICT innovation to daily functions (Peansupap and Walker, op.cit.).

Users should have an effective support system, not only at a training level or from top management, but also with regards to technical issues (Love et al. 2001, p. 34; Stephenson and Blaza 2001, p. 11). Without the support and ongoing process of training, personal learning gaps may develop, leading to users giving up on using ICT applications and ultimately developing negative perceptions towards its use (Stephenson and Blaza 2001). 
The delivery method of the support function is important. Remotely provided technical support may be perceived as negative, because many users prefer to have "hands-on" assistance to solve an ICT related issue- "show me" rather than "tell me" (Peansupap and Walker 2006, p. 373).

There is a requirement for intense management interventions to facilitate a supportive environment. From a management strategy perspective Bowden et al. (2006, p. 665) list objectives that should be attractive for management and therefore serving as motivation for management to support employing innovative ICT solutions: (1) reduction in defects and waste; (2) increased productivity, (3) better predictability; and (4) reduced operations and maintenance costs.

Many construction companies appear to have insufficient experience in understanding organizational and non-technological issues of strategic ICT adoption (Love et al. 2001, p. 36; Songer et al. 2001, p. 9). The purpose of this research project was therefore to compile a framework of socio-organizational issues that could guide and inform the management of the mobile technology adoption and diffusion process amongst managers in a construction company.

\section{Description of Organisational Setting for Research Project}

In this paper the authors focus specifically on mobile computing. The potential of mobile technologies to support and enhance operations in construction companies have been explicitly recognized (Suman et al. 2009, p. 398) although only investigated to a limited extent. Mobile devices for the purpose of this study include laptops (notebooks) with wireless LAN or WAN or 3G technology, smart mobile phones, and Personal Digital Assistants (PDA's) with 3G connectivity. In South Africa mobile penetration rates are quite high. ITU figures (International Telecommunications Union 2011) show that for 2010 the country had 91.24 mobile subscriptions per 100 inhabitants. The current smart mobile phone penetration rate is estimated at $16 \%$ and is expected to increase dramatically in the near future (Streicher 2011).

This study focused on a small-to-medium construction company based in Gauteng, South Africa. The aim of the project that forms the focus of the case study was to facilitate the process of mobile computing adoption that would allow the lead author (who is the IT Manager of the company) to identify, analyze and expand on the understanding of the main issues that should be considered in managing the adoption of mobile computing, specifically by managers. This objective was achieved by introducing mobile computing technologies to specifically identified users, monitoring the impact thereof, and documenting the findings and refining an explanatory framework for social issues related to mobile technology adoption in the company through a series of action-reflection cycles.

The company where the research took place is a medium sized construction company that has been active since 1995. Their current focus is civil work for the national energy supplier, residential property projects, and expanding on commercial property projects.

In most of the construction projects the company fulfils the role of main contractor and relies heavily on subcontractors for most of the actual construction work for a particular project. The company therefore requires robust administration processes that allow the successful administration of the payment certificate claims, and supplier and subcontractor payments.

The executive management team believes that ICT is vital. However, many of the experienced employees that fulfil managerial roles do not visualize the same benefit that ICT may hold to the overall productivity of their daily function. With this in mind the ICT 
technologies and packaged software applications employed, by some members of the management team, are quite impressive; however, this unfortunately only includes a handful of persons.

In some instances experienced employees are very keen to adopt innovative solutions, but the burden to acquire skills to successful adopt these innovative solutions seem to present barriers to the successful adoption thereof.

The Participants

Five participants (A, B, C, D \& E) were selected for participation in this research project. Each participant was deliberately selected in order to ensure a representative mixture of the divergent backgrounds, perspectives, levels of experience and qualifications and positions in the organisation (e.g. management vs. site agents): (1) Participant A (site agent for 4 years, practical experience, no formal tertiary qualifications), was selected based on middle management status and location at a construction site office; (2) Participant B (recent appointment, 10 years experience as Contract Manager, degree in construction management, attended a course in project management, dynamic, involved), was selected on the basis of his positive attitude towards research activities and issues; Participant $\mathrm{C}$ (post graduate qualification in construction management, 1 year experiences as junior contract manager), was selected on the basis of his potential interest in innovation through technological advancement as well as re-engineering of business processes; Participant D (tertiary qualification in 1977, site and contract management experience), was selected on the basis of his experience as site agent that had the potential to highlight many of the issues to successfully adopting mobile computing within this construction company; Participant E (Degree, 1979, contract management experience, founder of the construction company where the research was performed), was selected to enhance understanding and feedback related to the company's vision with regards to ICT technology employment and current business processes within the company. Also, inclusion of Participant E provided the study with the required organizational 'legitimacy' (Sarah et al. 2002, p. 540).

Figure 1 shows an organogramme of the participants that were selected for this research project.

\section{Need for mobile ICT}

In summary the following practical mobile computing related requirements were identified: (1) Managerial employees (middle management) need to access email from a construction site; (2) Employees on construction sites need to access head-office information resources and the in-house administration system; (3) Basic ICT literacy and ICT application knowledge are absent at all levels of the company.

The general belief was that the PDA device with a wireless internet connection and its associated applications would be the ultimate solution to enable mobile computing on site, and would therefore allow for more effective and transparent business processes.

Pre-conceptualised theoretical framework for mobile technology adoption in construction companies

A literature-based theoretical framework of socio-organizational issues in mobile technology adoption and use was compiled prior to commencement of field work (see Fig. 2). 


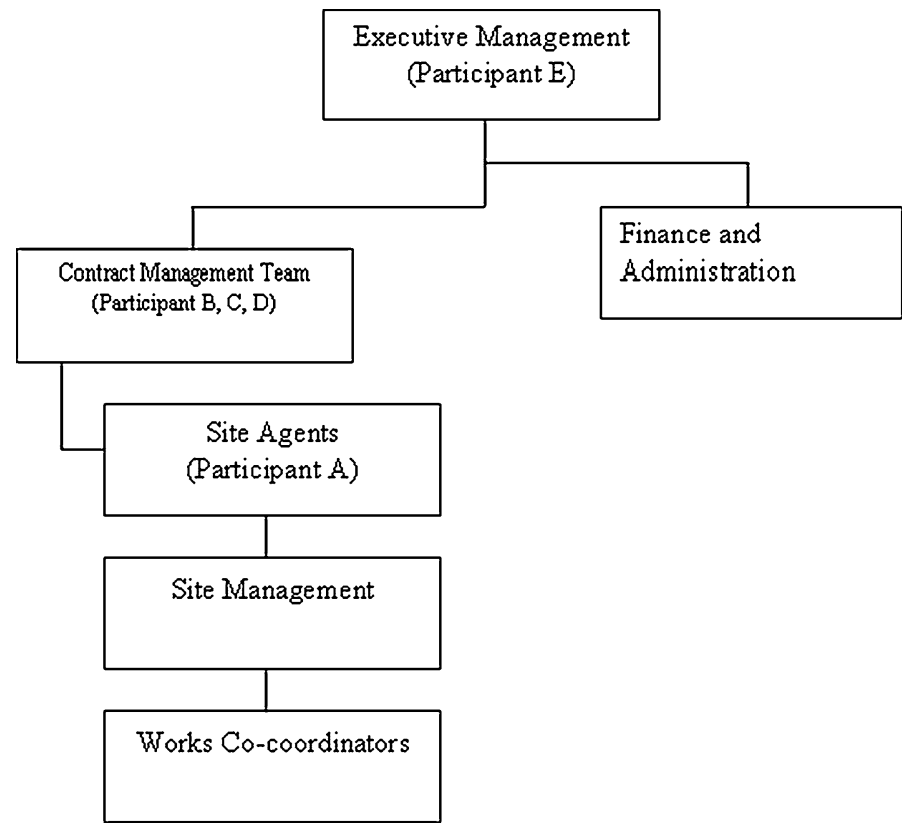

Fig. 1 Organogramme of the action research environment

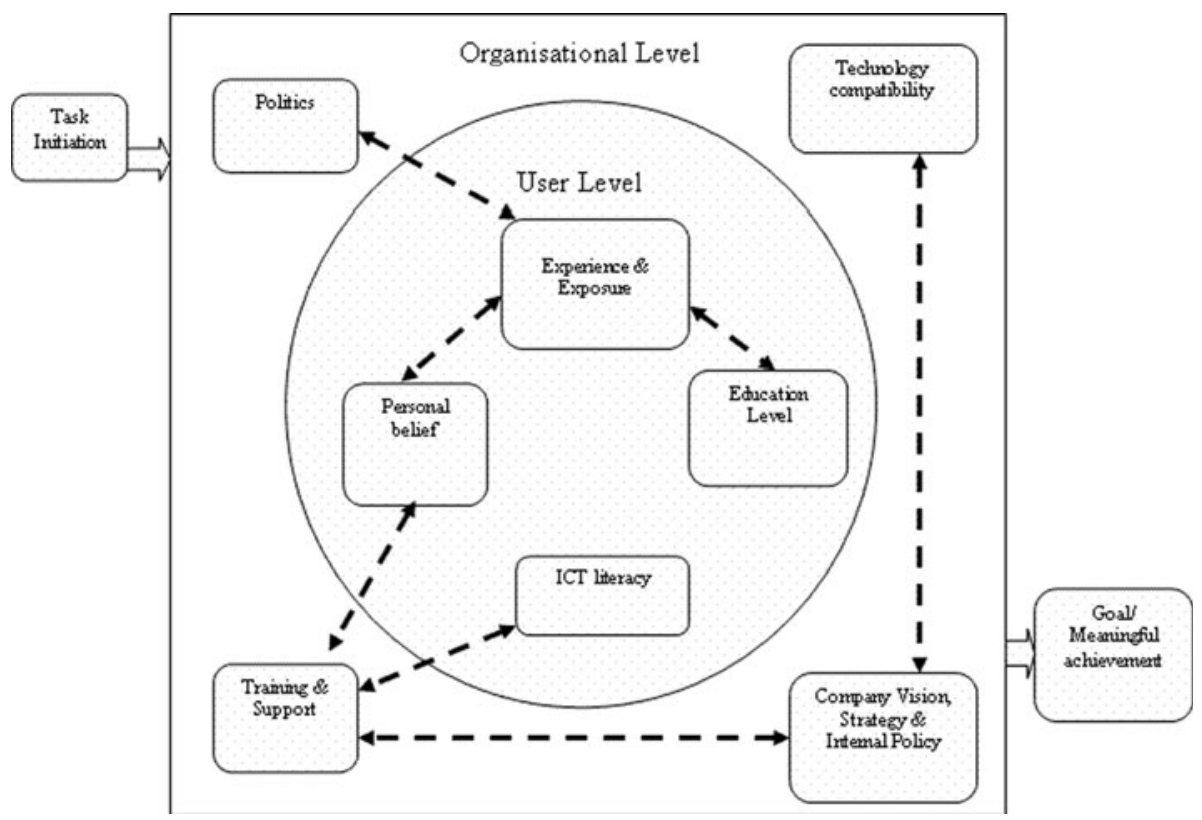

Fig. 2 A theoretical framework of pre-conceptualised mobile computing adoption and diffusion issues at this construction company 
This framework was largely informed by the work of Peansupap and Walker (2006), Love et al. (2001), Stephenson and Blaza (2001), Bowden et al. (2006) and Songer et al. (2001). The framework served the purpose of a hypothesis vehicle in the process of analysing the mobile computing adoption and diffusion issues at this construction company. The framework is graphically divided into four concepts: Task Initiation, Organisational Level issues, User Level issues, Meaningful achievement.

\section{Research Methodology}

AR as an Appropriate Method for Studying ICT Adoption and Diffusion

The researchers have used AR as method, which, in spite of its recognized significant advantage in allowing for researching management practice in its environment through active interventions (Davidson and Heslinga 2007, p. 20), and in spite of having been an acceptable research method for years in both Management Research (Eden and Huxham 1996, p. 75) and more specifically Information Systems (IS) research (Avison et al. 1999, p. 94), has not been extensively used to study ICT adoption and diffusion (Williams et al. 2009 , p. 7). As stated in the introduction to this paper the field of ICT adoption and diffusion is considered core to the IS discipline (Venkatesh et al. 2007, p. 268) and is therefore one of the most extensively researched areas in the discipline. Much of the mainstream research undertaken in this area has used the Technology Adoption Model (TAM) of Venkatesh et al. (2007, p. 268), yet this approach has been criticized for the absence of cultural and social considerations in understanding technology adoption and use (Bagozzi 2007, p. 247). By adopting AR, (as a necessity, given the considerations described in section "The need for a socio-technical perspective on ICT adoption in the construction sector") this paper moves away from the condition of "overall homogeneity" in ICT adoption and diffusion research, feared by Williams et al. (2009, p. 9) because of the widespread use of TAM. (These researchers (Williams et al. 2009, p. 7) could in their extensive survey of the field find only a single AR paper written in this field that was referenced in the ISI Web of Science). Limited examples of the use of AR in ICT adoption (and specifically in SMME's) include Davidson and Heslinga's (2007) investigation of ICT adoption by physicians in small practices, and Lambert's (2010) study of technology adoption in small law firms.

This research paper, through its use of AR, is able to demonstrate (albeit at a small scale) the interaction between social issues at individual (technology user) and organizational levels in understanding the adoption of mobile technologies by construction managers in the context of this case study. Thus it is argued (as indicated in the introductory section of the paper) that a socio-technical perspective on ICT adoption, combined with $\mathrm{AR}$ as a method provides a feasible solution to the persistent problem highlighted by Eckhard et al. (2009, p. 11) of integrating aspects of the social environments of users into adoption frameworks. This approach recognizes the organizational setting as socially complex, with the factors indicated by Argyris et al. (1985) becoming significant, i.e. (1) the researcher is embedded in the social situation and needs to collaborate with other participants; (2) technology adoption is essentially a social practice; (3) ideas for change are developed through deliberate reflective learning and (4) everything is subjected to critical inquiry. The strength of AR in this instance relates to the potential inherent in the method to allow integrated analysis of the impact of context on ICT adoption in an open, rather than closed system (Stephens et al. 2009, p. 473). 
Another consideration that indicated AR as research method for this study was the concern of the lead researcher in terms of the requirement that the research had to make a difference in practice and not only at a theoretical level (Gill and Bhattacherjee 2009, p. 668).

\section{AR Design Considerations}

The pragmatic 'real world' focus of AR is considered an advantage in the context of construction companies (Rezgui 2007b, p. 75). The AR approach that has been employed, has allowed a platform of introducing changes into a complex social process and observing the effects. The findings allowed the researchers to implement innovative mobile computing solutions, while adding to the theory of mobile technology adoption at construction sites.

The following considerations were taken into account in the crafting of an appropriate AR framework, based on Baskerville and Wood-Harper (1998): (1) The researcher is actively involved and an equal co-worker, with the environment being one in which, although the participants are not co-researchers, there is nevertheless free association, flow of information and choice of participation (Argyris and Schön 1989, p. 613), i.e. there is 'collaborative involvement' (Baskerville and Wood-Harper 1998, p. 94); (2) The researcher also fulfils the role of a facilitator in providing the participants with advice, guidance and help and because the researcher has to a large extent attempted to solve the research problem and determine what interventions should be enforced the researcher's role could also be referred to as 'expert involvement' (Baskerville and Wood-Harper 1998: op. cit.); (3) The primary goals of the research are both organisational development and scientific knowledge; (4) The preference of the lead researcher was for a fairly structured iterative approach.

A canonical action research process was therefore followed to allow for the enhancement of the competencies of the actors. Susman and Evered (1978, p. 588) specify activities or steps to be executed in a cyclical form, for each iterative cycle, to comply with the characteristics of a canonical action research form-these are diagnosing, action planning, action taking, evaluation and the specification of learning. The client-system infrastructure constitutes the research environment.

Figure 3 shows a diagrammatical representation of the overall AR design in line with the schema presented by Checkland and Holwell (1998, p.15).

In terms of de Guerre's (2002, p. 333) 'insider-outsider' distinction the lead author on this paper could be considered as an 'insider' in the organisation where the research was undertaken, while the second author, with only an academic supervisory role could be considered an 'outsider' with a more detached socio-technical research perspective. The lead author's 'insider' role allowed for realization of the benefits valued by Rolfsen et al. (2007, p. 54, 62) of firstly enabling understanding of the work practices in the organization, and especially the tacit dimension, and secondly enabling better understanding of organisational issues at affective level, thus resulting in enhanced trust relationships related to the research project.

\section{Research Project Structure}

The research tasks performed within this research project were defined as predetermined steps that were executed as iterative cycles (Table 1), until the research objectives were achieved. 


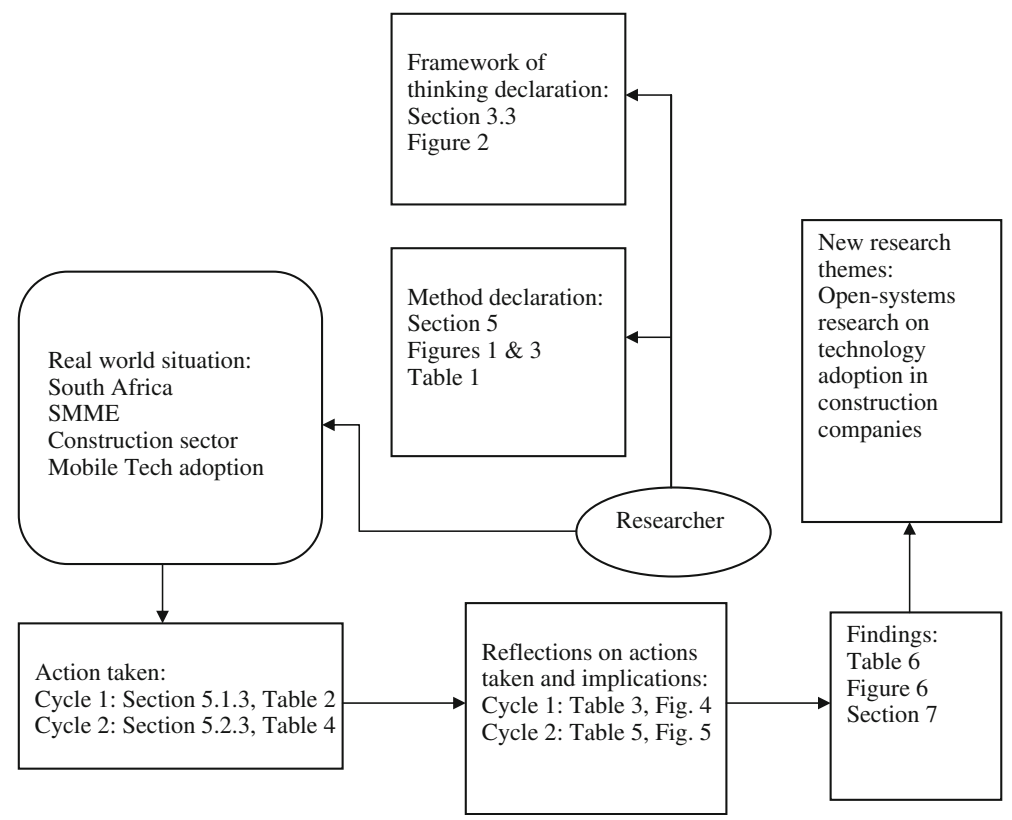

Fig. 3 Diagrammatic representation 'Framework, Method, Area of concern' (adapted from Checkland and Holwell 1998, p. 15)

The activities included in each iterative action research cycle were: the diagnosis of the research environment at the commencement of the cycle, action planning, action tasks executed in order to influence research environment, thereafter a process of evaluation of results, and finally the specification of learning aspects derived from the effect of the planned activities implemented in the research environment (Baskerville and Wood-Harper 1998, p. 96).

Because of a limited timeframe, the action research activity was completed within a period of 6 months and participation was limited to five carefully selected participants. Three interviews were conducted with each participant during the course of the project.

With reference to the steps or activities involved in each cycle (of Table 1), a brief description is provided of the research process that was followed. The actual process that was undertaken followed the recommendations of Baskerville and Wood-Harper (1998, p. 97) quite closely.

For the diagnosing phase of each cycle a set of questions were compiled that were derived from the learning aspects from the previous iterative cycle. This allowed the initiation of a discussion about the research topic with each selected participant. The questions enabled the researcher to better understand the research context of the participants with specific focus on "participant's qualification, experience \& skills", "participant's technology maturity and application", "participant opinion on the future of mobile computing in construction industry". From each discussion with the participants, the researcher and the participant collaboratively identified possible issues within the problem domain that are considered barriers to the successful adoption of mobile computing. The second cycle questions and discussion focussed on the "mobile computing issues" in light of the knowledge attained in the first cycle. These activities contributed to the development 
Table 1 A graphical illustration of the action research blueprint

\section{Action Research Cycle 1}

A complete conventional canonical action research (AR) cycle was completed within

AR Cycle 1. However we were able to contribute to the AR activity of specifying learning at as the cycle progressed through the steps of action planning and action taking. This is indicated by the dashed lines

Action Research Cycle 2

Again, a complete conventional canonical action research (AR) cycle was completed within

AR Cycle 2. However we were also able to contribute to the AR activity of specifying learning at as the cycle progressed through the steps of action planning and action taking

Action Research Cycle 3

A final interview was conducted to establish the learning aspects derived from AR Cycle 2. This also allowed a platform for recommendation that goes beyond the scope of this research project

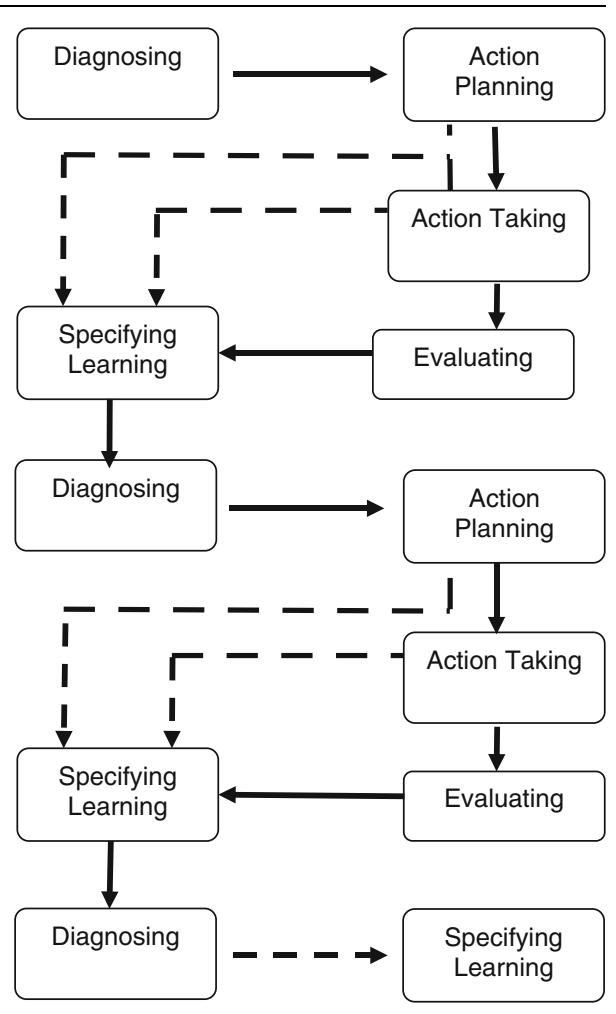

of theoretical assumptions about the organizational situation and the problem domain for each cycle executed. Again, from each discussion the researcher and the participant collaboratively identified possible issues within the problem domain that are considered barriers.

Action planning involved collaborating with the participants, to determine actions that would address the primary problem (Baskerville and Wood-Harper, op. cit.). The lead researcher (co-worker) asked the participants, what actions should be taken from a business process perspective to allow adoption and diffusion of mobile computing technology. Although the researcher consulted the participant for suggestions, the main researcher devised action planning events (guided by the thinking frame of section "Pre-conceptualised theoretical framework for mobile technology adoption in construction companies"), with approval from the participants.

During action taking the researcher and the participants collaborated in active intervention and effective realization of planned changes. For this particular research project the change was directive, with the direction coming from the researcher. Activities included establishing an environment where all participants were able to associate with the concept of "mobile computing". This was achieved by ensuring that all participants were able to work from a remote location and accessing electronic resources remotely. 
After the planned actions were completed, the researcher and participants collaborated to evaluate the outcome of the changes. The need was to determine whether the theoretical planned effects were realized, and whether these effects contributed to relieving the primary problem. The evaluation of planned actions was achieved by informal discussions with participants and co-workers. The main researcher also hosted planned workshops and individual interviews with the participant and fellow co-workers, to discuss and evaluate the planned actions. After these events the planned actions outcomes were analyzed and documented by the researcher. Thereafter the documented aspects of the activity of learning were used as feedback results that fed back in the next action research cycle.

Specifying learning was an ongoing process that had to be considered throughout the project. The knowledge gained from the outcome of a specific cycle was incorporated for further cycles. This was achieved by documenting learnt concepts that would contribute towards or impact on the outcome of the project. This was mainly achieved by continuous reflection on the problem domain and identifying concepts that implied a change in organizational belief with regards to mobile computing and the adoption thereof, or new knowledge that required reconsideration, for instance the notion of "peer pressure" that was not included in the initial thinking frame.

\section{Data Gathering and Reflection}

Date was gathered through (1) conducting one-to-one interviews and workshops; (2) employment of technology logging and monitoring tools to gather data of the implemented "action planning" activities; (3) an informal networking feedback process.

\section{Reporting Research Findings Based on the Action Research Cycles}

In this section the results from the action research activities are presented. These are presented as lessons learnt, and the modification of the initial literature-based socioorganizational framework (Fig. 2) after each research cycle.

\section{AR Cycle 1: Baseline Analysis}

The lead researcher's first actions were to ensure the appropriate technology has been employed at the observation points. This was done to ensure that the lack of availability of technology could not be considered as the primary barrier, thus allowing a focus on the socio-organizational issues.

The first cycle was intended to prime the participant's "thinking" in terms of the use and application of mobile computing as part of their daily function.

\section{Diagnosing}

Initially it seemed that the selected participants B and D were not equipped with appropriate technological devices. Therefore, it was decided to provide all participants with at least a laptop (notebook), or a Smartphone or PDA device which could connect to the Internet wirelessly or remotely.

Participants A, B and D did not seem very confident in applying the technologies available to them. The initial observation indicated that the users would definitely need 
training, specifically with regards to the application of the technology in their daily function. There was also an indication from them that they did not have the appropriate technical support if a technical problem arises.

\section{Action Planning}

Over a period of 2 weeks, interviews with each individual participant were held. The interviews focused on three main concepts: (1) Participants' current application and use of the mobile computing technology available to them; (2) Participants' technology maturity; (3) Participants' opinions of future mobile computing technology application within the construction industry. Although these interviews were based on a set of questions, the intent was to have open-ended discussions. Action planning events were identified on the basis of the participant interviews.

\section{Action Taking}

The actions listed in Table 2 were taken for each participant.

\section{Evaluating}

Participant Qualification, Experience and Skills It was expected that the mobile computing adoption barriers would be specifically manifested by the older generation participants, as well as participants that did not have a tertiary qualification. The older generation (participants A and D) have extensive practical experience in terms of project management and site activities and functions; according to these participants this is vital to their daily function. The younger generation, participants $\mathrm{B}$ and $\mathrm{C}$, seemed to be more eager in implementing new concepts that mobile computing technologies offer. Only participants A and $\mathrm{E}$ had prior knowledge of how to use a PDA device to receive email via wireless internet connectivity.

Participant A did not have any formal tertiary education but was able to use and employ a PDA device in his daily activities. Participant D has attained a tertiary degree, but did not

Table 2 Actions taken for each participant

\begin{tabular}{lll}
\hline Participant & Action & Comments \\
\hline A & $\begin{array}{l}\text { Issued with laptop because of PDA screen size } \\
\text { limitations }\end{array}$ & \\
B & Use existing equipment (VPN via broadband \\
& home Internet connection) \\
C & Provided with faster access to internal network \\
& through use of FTP site. & \\
& Provided with one-off training in use of FTP \\
& facility & \\
Originally traded desktop for laptop; however & \\
declined this at a later stage & Provided with weekly 1-h individual training & \\
& on various applications for 2 months & Provided action and approval for action \\
& & planning tasks for other participants \\
\end{tabular}


even have the skill to send an email via his desktop email communication application. The lead researcher had the pre-conception that a university graduate would have an attitude to constantly enrich him/herself. Therefore, generally accepted skill of sending and receiving an email message would have already been gained.

Participant E believed that there is a need to constantly enrich oneself with new knowledge to allow for progression in career endeavours. He has completed a number of courses from various non-tertiary institutions, constantly enriching his knowledge. According to him, this has allowed him to achieve above average enrichment and has narrowed knowledge gaps he experienced during the course of his career.

Participant Technology Maturity and Application Participants A, B, C and E were using some form of mobile computing device within their daily functioning, and all participants were using the Internet on a daily bases, for work and personal activities.

Participants B, C, and E have laptop computers, which can at least connect to the Internet, as part of their daily function. Participant A only has a PDA with wireless internet connectivity, and uses the email functionality on a daily basis. Participant D has a Smartphone with wireless internet connectivity, but only uses it for telephony.

All of the participants used the email facility provided by the company on a daily basis and were dependant on this facility. Bearing this in mind it is clear that a there is a need to receive emails on a Smartphone or PDA type device that will enable especially a contract manager to provide quicker feedback to the client or external project manager. It should also allow a contract manager to attend to problem issues in a more efficient manner; this is suggested by the time wastage factor when commuting between all the construction sites and the head office.

\section{Specify Learning}

Table 3 provides a summary of the learned aspects, the practical contribution that the action taking activities presented.

Figure 4 illustrates a revised theoretical framework of the substantiated mobile computing adoption and diffusion issues that has been identified within AR Cycle 1, as well as their interactions. The issues highlighted in grey refer are issues that were added based on learning from AR Cycle 1.

In addition, the following significant issues were noted: (1) Technology ('technology compatibility') is still a significant barrier; (2) Many of the participants were not aware of the available functionalities or technologies that would allow full access to administrative company resources; (3) 'IT support' structures needed to be in place; (4) Basic computer literacy ('ICT Literacy') was an issue. These issues were used to devise the action planning activities for AR Cycle 2.

AR Cycle 2: Strategic Planning

\section{Diagnosing}

AR Cycle 2 was intended to extract the participant's 'experience' with reference to the use and application of mobile computing as part of their daily function.

The significance of training was highlighted based on additional training requests from peers of participants after these peers noticed the benefits of the acquired technology skills. 
Table 3 Summarized practical and theoretical implications AR Cycle 1

\begin{tabular}{lll}
\hline Summary of learning concepts & Practical contribution & $\begin{array}{l}\text { Implication on the theoretical } \\
\text { framework: Fig. } 4\end{array}$ \\
\hline $\begin{array}{l}\text { Eagerness of participants A, B } \\
\text { and C regarding the }\end{array}$ & $\begin{array}{c}\text { Potential new ways in which the } \\
\text { technology can allow efficiency } \\
\text { implementation, and learning of } \\
\text { new innovative technologies, } \\
\text { suggested that better adoption } \\
\text { and diffusion scenario may } \\
\text { exists for mobile computing }\end{array}$ & $\begin{array}{c}\text { Although "personal belief" plays } \\
\text { an integral part of participant A, }\end{array}$ \\
identified & & $\begin{array}{l}\text { B ad C's eagerness, we also } \\
\text { need to be aware of the "stage } \\
\text { of their career" and their } \\
\text { "motivation" level, that may be } \\
\text { influential }\end{array}$
\end{tabular}
among the younger generation participants

There was no distinct correlation between the participant's formal "education level" and the impact it has on mobile computing adoption and diffusion

"Personal belief" and "training" are vital to the success of mobile computing adoption and diffusion

Mobile computing devices enable the use of email application software that has significant benefits for the functioning of the professional construction management team

Technology cannot be excluded, in our attempt to focus on social issues. Technology that enables mobile computing (wireless internet) poses an influential adoption and diffusion barrier

Limited awareness of functionalities and IT technology provided by this construction company, suggests revising the company's computer literacy training policy
The participants within this study have been positively influenced regarding mobile computing adoption and diffusion. They have influenced their direct peers with regards to use of mobile computing in their daily function

The ability to access and send emails wirelessly via mobile computing devices has positively impacted the efficiency of the communication channel users between this construction company and external professional team members

The available technology offered by service provider that provides wireless internet connectivity is considered an issue in the deployment of innovative solutions. Participants have acknowledged this and seek designated areas on a construction site that allows efficient wireless internet connection reception

The training policy with regards to IT literacy and mobile computing needs attention. The general IT literacy proficiency suggests that it has an effect on mobile computing adoption and diffusion. The need for a plan has been formulated, as well as an implementation policy to define the IT training methodology to be employed at this construction company
Although the participant's formal "education level", was believed to be significant it seems to that "personal belief", "stage of career", "motivation" and previous "experience and exposure" have more significant impact on "ICT literacy"

"Technology compatibility" is not the main barrier in the adoption and diffusion of mobile computing, but needs to be considered as in some cases required service delivery cannot be provided

This refers to "technology compatibility"

This construction company's "Company Vision, Strategy and Internal Policies" has a great influence on the objectives of this IT department including "Training and support". While the issue of "Training and support" influences "ICT Literacy" and impacts the mobile computing adoption and diffusion positively 
Table 3 continued

\begin{tabular}{lll}
\hline Summary of learning concepts & Practical contribution & $\begin{array}{l}\text { Implication on the theoretical } \\
\text { framework: Fig. } 4\end{array}$ \\
\hline $\begin{array}{l}\text { Users are unawareness of steps to } \\
\text { follow to attain IT support; } \\
\text { support structures are }\end{array}$ & $\begin{array}{l}\text { Participants and other users } \\
\text { within this construction } \\
\text { company have been made aware } \\
\text { methods of IT support had to be } \\
\text { revised }\end{array}$ & $\begin{array}{l}\text { This also substantiates the } \\
\text { significance of the pre- } \\
\text { conceptive issue "support" } \\
\text { insues. A more formal email- } \\
\text { based reporting system was } \\
\text { employed }\end{array}$ \\
\hline
\end{tabular}

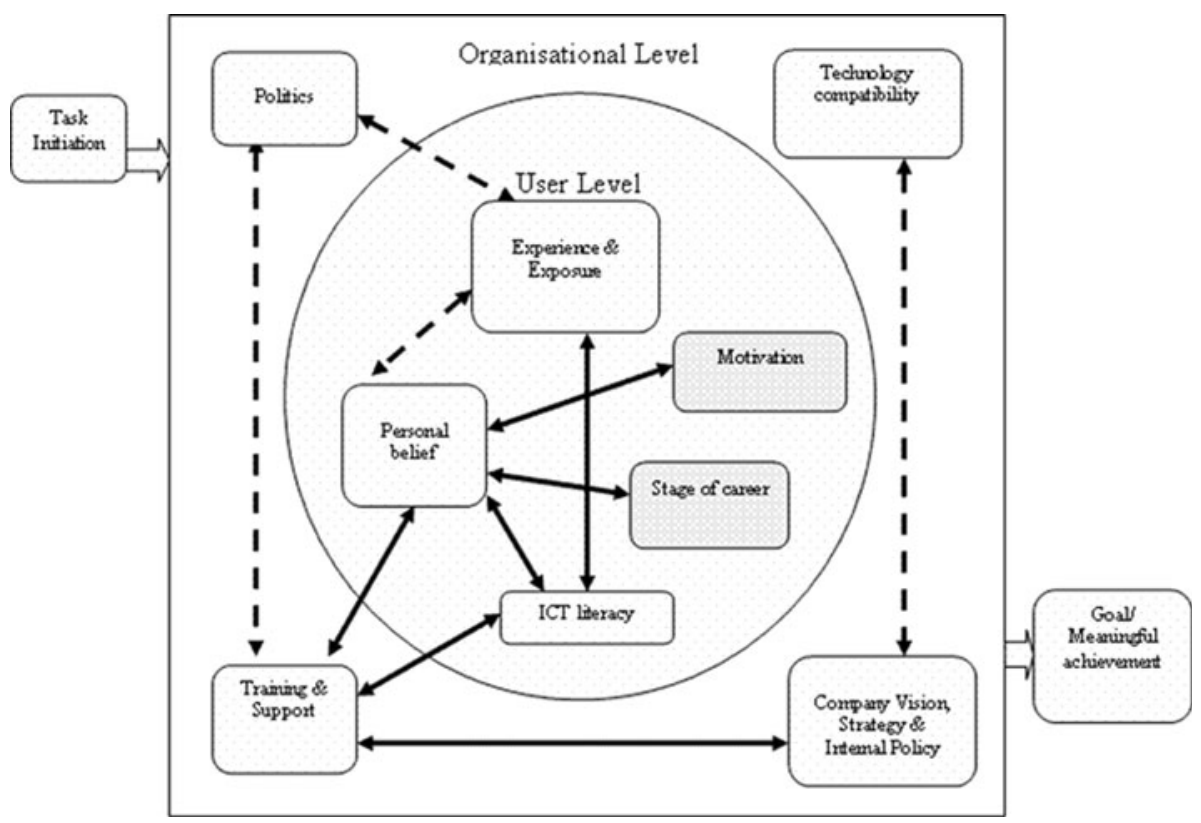

Fig. 4 A theoretical framework of pre-conceptive mobile computing adoption and diffusion issues as observed in AR Cycle 1

Some technology barriers were encountered: (1) Internet connection speeds, which improved slightly during the course of the project; (2) the limited screen size of PDAs, making it impractical to display this construction company's internal administration system in its standard format. The Internet Explorer functionality on the mobile device is also limited. Finding ways in which technologies could work conjunctively had to be found. For example, a contract manager would need at least a Smartphone with a wireless Internet connection and software that allows receiving and sending email wirelessly, a laptop with a wireless Internet connection modem with email application software and a company network that allows an environment that is conducive to mobility and allows the workforce to connect to the company internal computer network remotely.

The concept of 'support' needed to be expanded to include any technical computer issue to allow a situation conducive to computer literacy confidence building and had to include building an understanding of the benefits of mobile computing. 
Table 4 Action taking: Cycle 2

\begin{tabular}{lc}
\hline Training & $\begin{array}{c}\text { Events focused on the use and application of email communication software on a } \\
\text { mobile device like a Smartphone or PDA and a laptop workstation } \\
\text { Training was also provided in the application and use of the email } \\
\text { synchronization employed on a laptop or desktop workstation in conjunction } \\
\text { with a Smartphone or PDA device that can connect to the Internet wirelessly }\end{array}$ \\
$\begin{array}{l}\text { Technology application } \\
\text { IT Support }\end{array}$ & $\begin{array}{l}\text { Use of mature and newer technologies in conjunction (see examples below) } \\
\text { A formal approach was needed to report, document and track the progress of } \\
\text { reported IT issues. An intranet web portal: "IT Help Desk" was introduced }\end{array}$ \\
Executive management & $\begin{array}{c}\text { A policy was proposed and accepted by the executive management team that all } \\
\text { contract managers and site agents were to be issued with a company specified } \\
\text { Smartphone or PDA with wireless Internet connectivity, and a laptop with } \\
\text { company defined standard operating system, and a wireless Internet connection } \\
\text { modem }\end{array}$
\end{tabular}

\section{Action Planning}

It was decided to group certain participants together, based on their technology maturity and job description. The younger generation participants which included Participant $\mathrm{B}$ and $\mathrm{C}$ would be grouped together while Participant A, D and E would be interviewed individually. What was significant was the fact that fellow employees wanted to be included in the sessions. The reason provided by these employees for wishing to join the sessions was a desire for access to communications technology from construction sites. A group session was scheduled that included Participant B and C, with two fellow colleagues that fulfil the position of junior Contract Manager (same job description as Participant C) that wanted to join the session.

\section{Action Taking}

Action taking (see Table 4) focused on three main concepts-training, technology application and support. In the interviews we focused on how these concepts contribute or pose barriers to the adoption of mobile computing within this construction company.

\section{Evaluating}

This was done by exploring issues around the main concepts identified within this cycle, i.e. training, technology application, ICT support and technology application.

Training: The lead researcher's viewpoint was confirmed in terms of adjusting the training agenda's based on the user maturity levels.

Support: An environment that enables mobile computing needs support in terms of ICT literacy training, IT support and executive management support.

Technology application: All the impacted users were aware of the new functionalities and seemed to be employing it regularly.

\section{Specify Learning}

Table 5 provides a tabulated summary of the learned aspects and the practical contribution that the action taking activities presented.

Figure 5 illustrates the revised theoretical framework. The issues highlighted in grey are new issues that were added within AR Cycle 2. 
Table 5 Summarized practical and learning aspects for AR Cycle 2

\begin{tabular}{lll}
\hline Summary of learning concepts & Practical contribution & $\begin{array}{l}\text { Implication on the theoretical } \\
\text { framework: Fig. 5 }\end{array}$
\end{tabular}

Influential employees like Participant D inspired other employees to seek the same type of ICT literacy skills.

Although "Technology" has been considered a barrier, this barrier has been resolved by changing the perspective in terms of the "technology application".

Training, and the platform of provision, is vital to the successful adoption and diffusion of mobile computing.

With regards to IT support the similar concepts applies. The platform of IT support provision and the structure organizing the discipline is vital to the successful adoption and diffusion of mobile computing.

Support from management has an impact on the research objective, and as noticed in the testimonials of Participant E, provides direction and drive by means of the company strategy with regards to mobile computing adoption and diffusion.
Many employees that were not directly involved in this study have benefited from the drive among influential participants to learn new concepts specifically with regards to the email application software

By employing technology in conjunction like SMS and email, or changing the perspective of the application of the actual technology has allowed more efficient business processes. This also refers to VBA Excel application that allows the material requisition request to be submitted electronically, and the application can access requested building material efficiently.

The training provided has allowed users to be more efficient in approving orders. Users that attended the email application software training have acknowledged that the training has positively impact their communication skills

A more structure approach in terms of IT support has allowed the IT support resources to be more effective in their endeavours. Users have also benefited, as IT related problems are resolved in a more efficient and effective manner.

Senior site managers will benefit from the drive to issue all of them with a laptop and Smartphone device that can connect to the internet wireless. This should allow them access an email application wirelessly and compile an electronic material requisition. This is a more efficient approach compared to the paper based process.
The issue "politics", have been substantiated and has had a positive impact on mobile computing adoption and diffusion with this construction company

Previously we considered the issue of "technology compatibility". However, the technology available still allows mobile computing functionalities, we as users just need to apply it in the correct method. Therefore, although the technology compatibility is an issue, the issue of "technology application" is more relevant within this research project

As previously and substantiated, the issue of training is vital to the success of mobile computing adoption and diffusion.

In AR Cycle 1 we considered the "training and support" as a codependant issue. However, because of the extent of their impact on mobile computing we would like identify an "IT support" as a standalone issue with our theoretical framework

"Executive management support"-we have identified and new issue that stems from the issue "training and support" identified in the pre-conceptive theoretical framework. 
Table 5 continued

\begin{tabular}{ll}
\hline Summary of learning concepts & Practical contribution \\
\hline $\begin{array}{c}\text { Internal policy definition is vital } \\
\text { to support the drive of adopting } \\
\text { mobile computing within this }\end{array}$ & $\begin{array}{c}\text { Users are guided by policies that } \\
\text { are derived from the vision and } \\
\text { strategy defined by the }\end{array}$ \\
$\begin{array}{l}\text { executive management. Policies } \\
\text { communicate the executive } \\
\text { management's vision and }\end{array}$ \\
strategy with regards to mobile \\
computing deployment.
\end{tabular}

Implication on the theoretical framework: Fig. 5

Internal policy definition is vital to support the drive of adopting mobile computing within this construction company.
Users are guided by policies that are derived from the vision and strategy defined by the executive management. Policies communicate the executive management's vision and strategy with regards to mobile computing deployment.

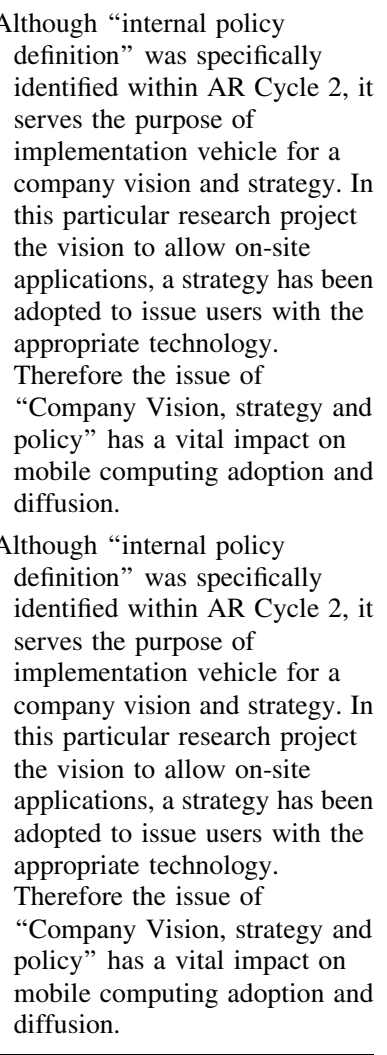

Although "internal policy
definition" was specifically
identified within AR Cycle 2, it
serves the purpose of
implementation vehicle for a
company vision and strategy. In
this particular research project
the vision to allow on-site
applications, a strategy has been
adopted to issue users with the
appropriate technology.
Therefore the issue of
"Company Vision, strategy and
policy" has a vital impact on
mobile computing adoption and
diffusion.
Although "internal policy
definition" was specifically
identified within AR Cycle 2 , it
serves the purpose of
implementation vehicle for a
company vision and strategy. In
this particular research project
the vision to allow on-site
applications, a strategy has been
adopted to issue users with the
appropriate technology.
Therefore the issue of
"Company Vision, strategy and
policy" has a vital impact on
mobile computing adoption and
diffusion.

AR Cycle 3: Realised Benefits

Within AR Cycle 3, as suggested by the research blueprint, the final interviews with the participants were held to understand the effects that the action taking and learning aspects from AR Cycle 2 (and by implication cumulatively including AR Cycle 1) have allowed. The interviews were conducted via informal discussions with Participant A, B, C and D. Guidance from Participant E was extracted, and any learning feedback was provided to Participant E.

The following sub-sections provide explanations of the issues that are perceived as influential to the process of mobile computing adoption and diffusion, followed by the learning aspects for AR Cycle 3.

\section{Diagnosing}

The adoption process of a policy to provide all senior site managers and site agents with mobile computing devices has been impacted on by budgetary and service delivery constraints. 


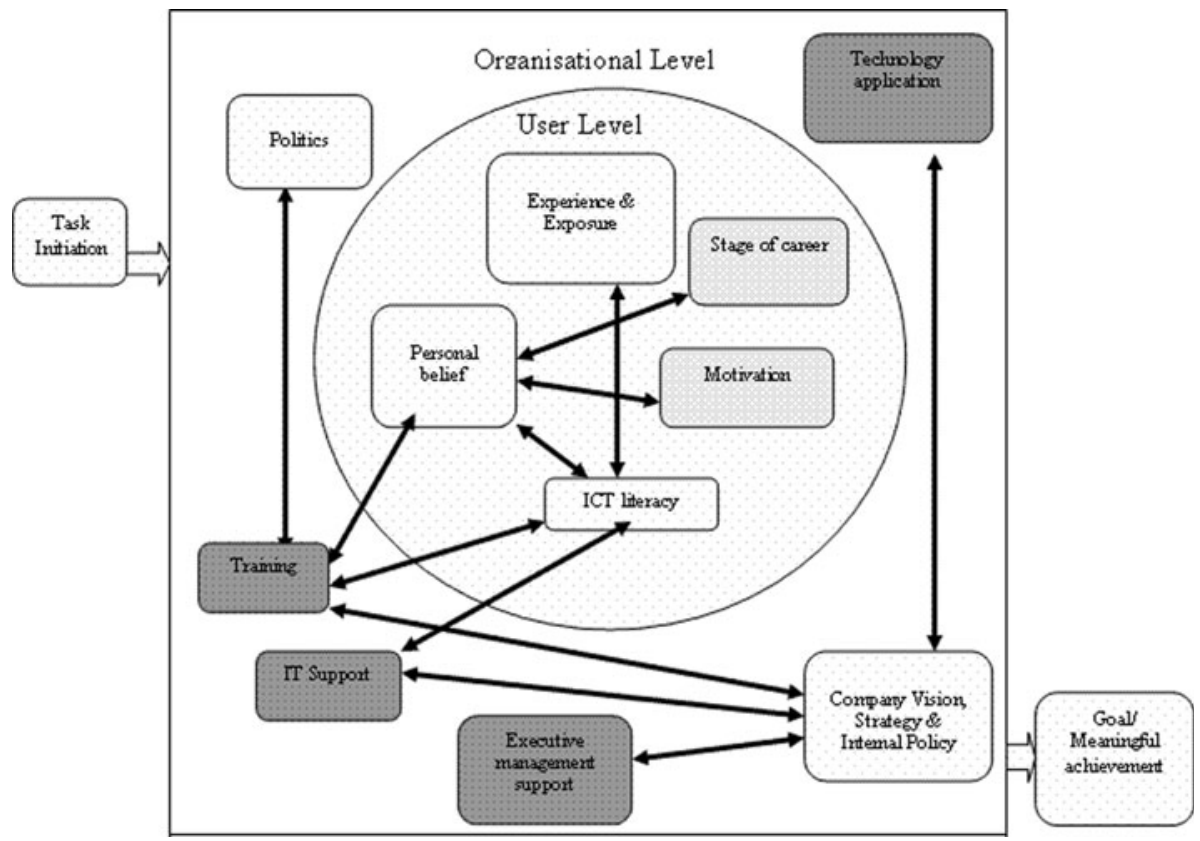

Fig. 5 A theoretical framework of pre-conceptive mobile computing adoption and diffusion issues as observed in AR Cycle 2

Within AR Cycle 2, as part of the action taking activities an extensive ICT training strategy that involved most of the employees at the head office was employed. The situation suggested that training should be provided regularly.

\section{Specify Learning}

AR Cycle 3 could be considered an extension of AR Cycle 2 (and cumulatively of AR Cycle 1 as well, as previously stated); however, the purpose of the new cycle was to allow reflection on the effect of the action taking activities implemented and derived within AR Cycle 2. This was mainly due the slow implementation of planned activities, as time passed, and the identification of a vital action taking activity-implementing a policy that states that all senior site managers and site agents should be issued with mobile computing technology. Therefore a true reflection of this action taking activity was only observed within AR Cycle 3.

Table 6 provides a tabulated summary of the learned aspects derived within AR Cycle 3 .

In conclusion the revised framework that has been devised in AR Cycle 2 did not change. The learned aspect within AR Cycle 3 was the significance of the organizational factors of 'company vision, strategy and internal policy', 'training' and 'technology application' in the process of successful mobile computing adoption and diffusion with this construction company. Figure 6 illustrates the final version of the theoretical framework of the issues and the underlying interactions as it has been derived throughout the AR Cycles within this projects. 
Table 6 Summarized theory and practical aspects for AR Cycle 3

\begin{tabular}{lll}
\hline Summary of learning concepts & Practical contribution & $\begin{array}{l}\text { Implication on the theoretical } \\
\text { framework: Fig. } 6\end{array}$
\end{tabular}

A policy has provided the drive with regards to mobile computing diffusion among site employee. Although the process is slow, it seems to be effective

Training should be provided on a regular basis and in an intimate manner, to allow the successful knowledge attainment

Wireless internet technology has improved during the course of the research project, but extensive benefits are not perceived by all participants

Mobile computing devices have not been fully adapted to function optimally in the daily construction site situation, but may still be applied in such a way that benefits can be derived
A more efficient formal communication channel is available to the senior employees on site

Senior site managers and site agents are attaining new skills with regards to ICT literacy

Certain urban locations allow users to access the internet at true broadband internet throughput

\section{More affordable mobile} computing devices (Smartphone) available from cellular service providers, that allow the same functionality as a PDA type device, can be issued to users
The "company vision, strategy, and internal policy, is vital to the drive of mobile computing diffusion

"Training" is vital to the success of mobile computing technologies

The application of technology is significant and should always be considered in the endeavour to extent business processes to site employees within this construction company

PDA devices are not the ultimate technology device to enable mobile computing diffusion. Smartphone technology can be applied in such a way that it offers the same benefits that PDA devices offer

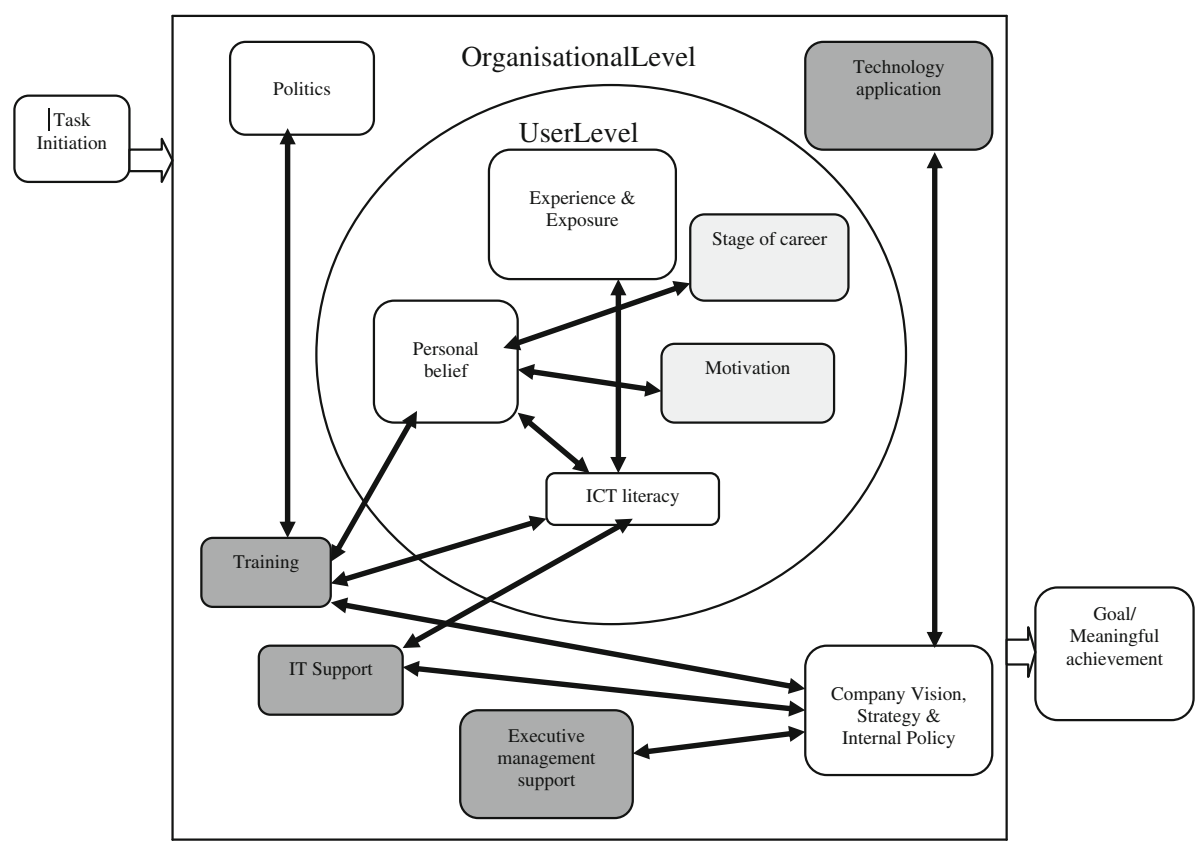

Fig. 6 A theoretical framework of the mobile computing adoption and diffusion issues within this construction company 


\section{Summary and Conclusions}

\section{Study Limitations and Contribution}

The scope of the project was obviously limited, but the study does constitute valid AR in terms of its design and execution. The authors would argue that in spite of its limited scope, the study does contribute in various ways, both at local and more general levels.

At local level (Martí and Villasante 2009, p. 390) the study contributed to the improvement of local practice through the introduction of technology into a construction SME. The process of mobile computing adoption by introducing action research planned changes within the research environment that allowed the main researcher to practically identify and analyze the literature suggested issues that should be considered in the extensive adoption of an ICT technology like mobile computing, specifically at managerial level within this construction company. This objective was achieved. Concurrently a substantive theory of technology adoption in a South African SME in the construction industry was developed in which the factors of 'stage of career' and 'motivation' are indicated as being meaningful. The authors do not argue for generalisations of these findings beyond the boundaries of the study itself, nevertheless the paper thus contributes to the limited available literature on mobile technology adoption and use (and especially from a socio-technical perspective).

The potential of this study for an impact at the 'public knowledge' level (Martí and Villasante 2009, p. 389) is at two levels. In terms of the view of AR as two parallel cycles (McKay and Marshall 2001, p. 53) the generalisation at the problem solving level constitutes the thinking framework that conceptualises technology adoption in construction companies as a complex socio-technical process that integrates contexts both at individual and organisational level. At the research process level the generalisation is that, given the complexities presented by the construction sector and the importance of understanding and integrating context into the understanding of ICT adoption, it could be expected that conventional mainstream approaches such as TAM will continue to experience persistent challenges in explaining ICT adoption and use in the construction sector. The authors would therefore argue for a more extensive adoption of use of AR in the construction sector. The construction sector as focus area for ICT adoption studies also becomes interesting.

\section{Recommended Further Research}

In general the challenges posed by organisational and spatial-temporal complexities in the construction sector seem to have hampered adoption and use of ICT relative to other industry sectors. This would be an indication of the persistent nature of the challenges posed to those championing ICT adoption and use as a result of conditions in this sector, and specifically in terms of the interaction between projects on-site and other units and sections of construction companies. An interesting contra-indication on this project (mentioned in section "Action planning") was the fact that participants voluntarily joined the research in order to get access to technology. Further research into the socio-technical nature of the complexities and tensions involved in ICT adoption and use in the construction industry should therefore prove to be insightful and productive.

The authors argue that an open-systems approach such as AR holds much potential for knowledge generation in this complex field. Carefully designed AR projects have the inherent potential to link construction management theory building with practice-focused 
action taking - thus becoming a powerful tool for construction ICT managers in linking theory and practice.

\section{References}

Argyris C, Schön DA (1989) Participatory action research and action science compared: a commentary. Am Behav Sci 32(5):612-623

Argyris C, Putnam R, Smith DM (1985) Action science-concepts, methods and skills for research and intervention. Jossey-Bass Inc., San Francisco

Avison D, Lau F, Myers M, Nielsen PA (1999) Action research. Commun ACM 42(1):94-97

Bagozzi RP (2007) The legacy of the technology acceptance model and a proposal for a paradigm shift. J Assoc Inf Syst 8(4):244-254

Baskerville R, Wood-Harper AT (1998) Diversity in information systems action research methods. Eur J Inf Syst 7:90-107

Bowden S, Dorr A, Thorpe T, Anumba C (2006) Mobile ICT support for construction process improvement. Automat Constr 15:664-676

Checkland P, Holwell S (1998) Action research: its nature and validity. Syst Practice Action Res 11(1):9-21

Davidson E, Heslinga D (2007) Bridging the IT adoption gap for small physician practices: an action research study on electronic health records. Inf Syst Manage 24:15-28

De Guerre DW (2002) Doing action research in one's own organization: an ongoing conversation over time. Systemic Practice Action Res 15(4):331-349

Eckhard A, Laumer S, Weitzel T (2009) Who influences whom? Analyzing workplace referents' social influence on Itadoption and non-adoption. J Inf Technol 24:11-24

Eden C, Huxham C (1996) Action research for management research. Br J Manag 7:75-86

Gill G, Bhattacherjee A (2009) Fashion waves versus informing: response to Baskerville and Myers. MIS Quart 33(4):667-671

International Telecommunications Union (2011). Mobile cellular subscriptions. http://www.itu.int/ITU-D/ ict/statistics. Accessed 25 July 2011

Jacobsson M, Linderoth HCJ (2010) The influence of contextual elements, actors' frames of reference, and technology on the adoption and use of ICT in construction projects: a Swedish case study. Constr Manage Econ 28(1):13-23

Lambert JT (2010) Pursuit of the elusive antecedents: action research unveils factors influencing technology adoption by small law firms. Syst Pract Action Res 23:251-267

Love PED, Irani Z, Li H, Cheng EWL, Tse RYC (2001) An empirical analysis of the barriers to implementing e-commerce in small-medium sized construction contractors in the State of Victoria, Australia. Constr Innovation 1:31-41

Martí J, Villasante TR (2009) Quality in action research: reflections for second-order inquiry. Syst Pract Action Res 22:383-396

McKay J, Marshall P (2001) The dual imperatives of action research. Inf Technol People 14(1):46-59

Nova Scotia Construction Sector Council (2010) Functional information technology-Phase 1: Detailed analysis. Nova Scotia Construction Sector Council Report, Nova Scotia

Peansupap V, Walker DHT (2006) Information communication technology (ICT) implementation constraints: a construction industry perspective. Eng Constr Architectural Manage 13(4):361-379

Rezgui Y (2007a) Exploring virtual team-working effectiveness in the construction sector. Interact Comput 19:96-112

Rezgui Y (2007b) Role-based service-oriented implementation of a virtual enterprise: a case study in the construction sector. Comput Ind 58:74-86

Rolfsen M, Johnsen A, Knutstad G (2007) Action engagement: improving researchers' involvement in action research projects. Syst Pract Action Res 22:53-63

Rowlinson S, Croker N (2006) IT sophistication, performance and progress towards formal electronic communication in the Hong Kong construction industry. Eng Constr Architectural Manage 13(2):154-170

Sarah R, Haslett T, Molineux J, Olsen J, Stephens J, Tepe S, Walker B (2002) Business action research in practice - a strategic conversation about conducting action research in business organizations. Syst Pract Action Res 15(6):535-546

Songer AD, Young R, Davis K (2001) Social architecture for sustainable IT implementation in AEC. Paper presented at the CIB-W78 International Conference, IT in Construction in Africa 2001 Conference, Mpumalanga, South Africa, 30 May-1 June 
Stephens J, Barton J, Haslett T (2009) Action research: its history and relationship to scientific methodology. Syst Pract Action Res 22:463-474

Stephenson P, Blaza S (2001) Implementing technological change in construction organizations. In Coetzee G, Boshoff F (eds) IT in construction in Africa, CIB-W78 International Conference, Mpumalanga, 30 May-1 June 2001

Streicher P (2011) SMS and smartphones. http://mybroadband.co.za/news/cellular/18237-sms-and-smart phones.html. Accessed 25 July 2011

Suman N, Ursic D, Psunder M, Veselinovic D (2009) Mobile information and communication technology and management of business changes in construction companies in Slovenia. Syst Pract Action Res 22:397-411

Susman G, Evered (1978) An assessment of the scientific merits of action research. Adm Sci Q 23(4): $582-603$

Venkatesh V, Davis FD, Morris MG (2007) Dead or alive? The development, trajectory and future of technology adoption research. J Assoc Inf Syst 8(4):267-286

Williams MD, Dwivedi Y, Lal B, Schwartz A (2009) Contemporary trends and issues in IT adoption and diffusion research. J Inf Technol 24:1-10

Yetton PW, Johnston KD, Craig JF (1994) Computer-aided architects: a case study of IT and strategic change. Sloan Manage Rev 35(4):57-67 